Article

\title{
Are You Environmentally Conscious Enough to Differentiate between Greenwashed and Sustainable Items? A Global Consumers Perspective
}

\author{
Mariusz Urbański ${ }^{1, *}$ and Adnan ul Haque ${ }^{2}$ \\ 1 Faculty of Civil Engineering, Akademicka 3, Częstochowa University of Technology, \\ PL-42-200 Czestochowa, Poland \\ 2 Business Management Faculty, Yorkville University, 2000 Steeles Ave W, Concord, ON L4K 4N1, Canada; \\ ahaque@yorkvilleu.ca \\ * Correspondence: murbanski@interia.eu
}

Received: 16 December 2019; Accepted: 13 February 2020; Published: 27 February 2020

check for updates

\begin{abstract}
Environmentally sustainable (green) products are frequently advertised to consumers, yet it is debatable whether the consumers are aware whether these green labelled products are environmentally friendly or not. Greenwashing is a phenomenon used by companies to sell their products. Through stratified (probability) and purposive and convenience (non-probability) sampling techniques, an online survey was circulated to gather information from 768 participants from the UK, Canada, and Pakistan to determine consumers' perspectives on subjects including awareness, trust, and effectiveness regarding greenwashed labelled products. The results were tested using the Chi-Square test for ranked data and structural equation modelling (SEM) for ordinal data. The study found that participants ranking themselves High environmentalists in comparison to Low and Moderate environmentalists, despite being skeptical, fall into the trap of identifying greenwashed products as sustainable. It has been proven that greenwashing negatively impacts the green purchasing behavior of the consumers. Participants reported that products are believed to be sustainable due to the overall perception of the product labelled as greenwashed. There is statistical evidence that purchase intent is not affected by greenwashing. It is also reported that younger people in comparison to older people have less trust and often believe greenwashing is problematic. Consumers were found to be vulnerable and more sensitive when their attention was drawn towards greenwashing. There is a need to educate consumers and improve policies to ensure consumers understand the real labels as greenwashed products are used in daily life.
\end{abstract}

Keywords: consumer perception; effectiveness; greenwashing; green purchase behavior; purchase intent; trust

\section{Introduction}

Are "environmental concerns" a concern for consumers? If so, when and why? These are the questions that trigger this research. At present, it appears that adequate measures and steps for protecting the environment are being taken by companies in order to survive [1]. This has led to a "green" strategy adoption by companies. The range of products involved includes paper towels, cleaning products, light bulbs, makeup, and all those appliances that could offer "green" alternatives, reflecting the belief of organisations that green marketing helps improve the sale of products by labelling them differently, as well as sustainable for the environment. This also indicates that organisations are producing products that are sustainable for the environment with no harmful effect on their surroundings. The organisations need to consider and adopt procedures that are important for showcasing green philosophy because society and various types of stakeholder are concerned about 
global warming and its potential effect on the green environment [2]. The organisations are using a green strategy by labelling products as recyclable or environmentally friendly, while some even opt for physically green packaging because the strategy has proved successful in attracting consumers. However, not all environmental claims by all companies are authentic, as some only intend to mislead consumers [3]. This misleading phenomenon is regarded as greenwashing. It creates skepticism and confusion among consumers while, to a larger extent, eliminating the demand for innovative green products $[4,5]$. Human consumption in both emerging and advanced economies has increased; therefore, the environmental consequences have grown, so products and companies must become greener and more environmentally responsible. Many organisations make claims of being environmentally friendly. Environmental claims are even made by those that are inherently not environmentally friendly, such as nonhybrid cars, plastic bottles, and airline flights [3]. Often, some green advertisements convey complicated truths, which lack the necessary information regarding the genuine environmental aspects of their respective products $[3,6]$.

Environmentalists and scholars have stated that regulatory attempts are nonbinding guidelines that do not protect consumers adequately from the adverse effects of greenwashing [7]. From the consumers' perspective, it is worrisome that various environmental aspects of products, namely, sustainability, are not verifiable even when consuming products that falsely claim it $[8,9]$. In fact, previous studies have shown that perceptions of greenwashing are linked with higher negative evaluations of brands and advertisements [10,11], while evidence also proposed that consumers with higher expertise in environmental matters are not fully resistant to greenwashing in advertisements [12]. This leads to questions such as whether consumers believe items are more sustainable with a greenwash label than those without one? Are consumers actually skeptical of the claims of greenwash labels and does this affect their purchase intentions? Are consumers aware of a product's label being greenwashed?

Across the globe, there has been an enormous increase in private consumption [13]. In the context of the considered economies, the private consumption of the UK accounted for $65 \%$, Canada $67.9 \%$, and Pakistan $82.1 \%$ of its nominal GDP in June 2019 [14]. All three considered economies have been found to have had a higher private consumption rate in the last five years and continue with an unsustainable consumption rate that has an extreme consequence on the environment. With the magnitude of consumers increasing across the globe, there is more conscious awareness about environmental issues, which has led to claims of willingness to partake in sustainable consumption [1]. This is the reason behind consumers' attitudes, and why green products, green brands, and green organisations are so much in demand. From 2009, there has been a 51-59\% increase in consumers who prefer to buy sustainably produced products $[14,15]$. On a global platform, the concerns vary, as in Canada, $69 \%$ reported to care about the social responsibility of the organisation, in the UK, $70 \%$ agreed, while in the emerging economies like Brazil, Pakistan, and China, $85 \%, 74 \%$, and $94 \%$ care about the social responsibility of companies, respectively $[14,15]$. Consequently, higher green aspects of products are advertised.

However, the desire to be successful by means of creating appeal, and concern for the environment among consumers, lead to greenwashing. At times, companies use marketing and advertising strategies to claim they are green while they lack actual implementation of any practices that could reduce their adverse environmental impact. It is largely found that broad claims are made because it is not in the best interest of companies to reduce their low environmental performance or share such details with consumers [11].

"The aim of this research is to identify the actual tendency of people claiming to be environmentally conscious in differentiating between sustainable and greenwashed products". Hence, the objectives of the study include the following:

- To evaluate to what degree environmentalists are more skeptical when identifying greenwashed products as non-sustainable. 
- To examine how a higher degree of green purchasing behaviour in comparison to the others (low and moderate green purchasing behaviour) means a higher tendency to restrain from using greenwashed products.

- To assess false labels, irrelevant labels, and vague labels affecting consumers' perception.

- To examine greenwashing affecting purchase intent and green purchase behaviour.

\section{Literature Review}

Before proceeding with the review of literature at hand, the key variables are defined below:

\subsection{Definitions}

\subsubsection{Greenwashing}

According to Halverson [1], "greenwashing is an existing fact or situation where organizations amplify and stress upon green features to extent that they even make false claims by misleading consumers and attract them to consume their products". It is defined as "deceptive or misleading environmental claims, which are false, vague, omit key information or a combination of these" $[1,3,7]$. In this study, false, vagueness, and irrelevant labels are the components of greenwashing.

\subsubsection{Vague Label}

Under greenwashing phenomenon "vagueness or vague label is a sin by the organization/producer to poorly define features or broad claims that cause intended consumers to misunderstand claimed features" [16]. For instance, "non-toxic", "all-natural" or "green". Though it appears positive, further exploration causes one to think what these claims mean? Such as an all- natural claim when mercury or uranium could have been used in some products making them poisonous $[1,16]$.

\subsubsection{False Label}

This is a sin of the fake label where a product might have used images or words to reflect nonexisting third-party endorsement [16]. For instance, the use of completely meaningless eco- labels such as "Certified Green" in order to represent the product being more legitimate so people can buy it [1]. Often companies use such labels on the packaging of their products as tested by so and so laboratory or certified by so and so research company while in actual fact such third-party endorsement does not exist.

\subsubsection{Irrelevant Label}

Claims by the company that appears to be likely true but not useful in the actual determination of whether the product is more environmentally friendly [16]. Such claims distract consumers and push them to use products labeled as environmentally beneficial [16]. For instance, in the USA, chlorofluorocarbon (CFCs) claims by companies that their products are free from CFCs, reflect the product is "greener" than others because they are CFC-free [16].

\subsubsection{Environmentalist}

According to Hirose [17] we have the following, "the general attitude (goals intentions), behaviour, and intentions to take certain actions that are environmentally friendly. The actions and intentions of individual reflecting environmental responsibilities (believing that taking action to save the environment from pollution and destruction is necessary) and the effectiveness of measures (believing that taking appropriate measures can solve environmental problems). Adequate knowledge and skills to understand and assess the environmental friendliness, cost versus profit, and social norms". Thus, from consumer behaviour studies' perspectives, the environmentalist is an individual who cares 
about the environment and has intentions to consume products that have no or minimal negative impact on the environment.

\subsubsection{Green Purchasing and Green Purchase Behaviour}

Chan [18] states that green purchasing reflects buying environmentally friendly products in order to avoid products having a harmful effect on the environment. It is often measured through the behaviour and intention of the consumers willingness to purchase green products [19]. Green purchase behaviour shows socially responsible behaviour through ethical decision-making [19]. Thus, the behaviour of a consumer who takes into account the public consequences of his/her private consumptions therefore ensures that products are bought that bring positive social change while reducing harmful effects on the environment.

\subsection{Greenwashing Phenomenon}

With the rapid growth in the green product market, there is also an increase in greenwashing suit [5]. Greenwashing is relatively extensive and therefore, studies have shown significant effects for the environment, consumers, corporations and authentic green products [1] and green skepticism has emerged. Green skepticism is a distinctive phenomenon where a product's green claim and legitimacy is doubted by the consumers [20]. It frequently arises among consumers who feel that there is a contradiction between what a company advertises and the actual practice, and hence, are of the opinion that the company is using greenwashing [4]. Thus, it creates suspicion among consumers, which is a serious concern. Interestingly, studies reported that approximately fifty percent of consumers might have reservations about environmental advertising claims [21,22]. As a result, it has been found that consumers could be angry and doubtful about all products and environmental claims due to greenwashing [16]. Furthermore, the knowledge of consumers and their concern for the environment is reduced by green skepticism [23]. Hence, having skepticism about green products can have severe consequences. Consumers feel betrayed and loss of trust emerges among them regarding corporations due to use of greenwashing [24]. Nevertheless, such doubts could be a positive thing because consumers could be driven to seek more information about the authenticity of a product by reading views, asking friends, checking websites, reading certification credentials, and so on. It is also possible that negative word-of-mouth information to such consumers would make them more aware of greenwashing [20].

At times, individuals who are more influenced by the opinions of others can take the judgement of a product relatively and seriously. This is an effective method of elimination of untruthful organisations that practice greenwashing $[1,3,24]$. On the other hand, excessive greenwashing could have grave consequences on the companies that are really making genuine efforts to be green [1]. It is also suggested to the managers that rather than have too much focus on green advertising to help the brand and purchase intent of the consumers, the focus should be on developing green aspects because overemphasis on green advertising can cause more harm than good [11]. There is a risk for companies to disclose a product's environmental impact as potential business could be lost [25]. Interestingly, a potential solution is recommended that companies should express their environmental concerns along with acknowledgement of their economic motives [25]. However, there is a lack of thorough research to support this notion. Often corporations exhibit environmental advertising as a promotional stunt for business, and it could perhaps work only if the focus of adverts shows the current perception of the consumers [26]. However, in case there is a lack of knowledge among consumers about the company's philosophy of not being environmentally conscious, then such environmental adverts would have a negative impact on the company [1]. Green advertising could be effectively used for creating an impact on purchase intent and behaviour, but companies avoid false environmental claims in order only to create positive green brand awareness as it is in their best interest [27]. Studies widely use the attribution theory as a potential predictor of reactions of consumers to greenwashing. The attribution theory demonstrates how "consumers explain others' behaviour by 'attributing' causes to what they 
may observe" [11]. In the context of green advertising, the theory is viewed as, "if a consumer observes the disconnect between a firm's communications and their actual behaviour, they may begin to investigate why they said that and whether it is honest" [11]. The same study also revealed that green advertising could negatively affect companies because if the companies' performance is negative, then green advertising will show lower brand attitudes more than the normal adverts [11]. On the other hand, it could play a role in elimination of the green market and further innovation [20]. Green product innovation incentives would be side-lined, and environmentally friendly product development would be hindered $[11,20]$. There is evidence that consumer perceptions of greenwashing products are genuine and factual, and such perception has a significant impact on purchase intent and brand attitude [11]. Additionally, the potential environmental benefit is lost due to the greenwashing [16]. There is a possibility that consumers with good intentions for buying green products might be misled into buying items that are contradictory to their environmental claims [16]. Consequently, the potential benefit of green purchase would disappear [16].

\subsection{Components of Consumers Perception}

\subsubsection{Consumers Perception}

Consumer perception reflects the opinion of the consumers about the products or services of the organization [1]. It is invaluable in determining the quality and differentiating the brand from other products. In this study, consumer perception is reflected through identifying and interpreting sensory information and components to measure trust, awareness, and effectiveness of products on consumers. The trust, effectiveness, and awareness about the product itself is part of a consumer's perception, which is also considered in this study.

\subsubsection{Trust}

Trust is essential to form relationships among customers towards products or services [24]. The level of market orientation perception affects the level of trust of the consumers [24]. In this study, the trust of the consumer is about labelled products as to how he/she believes the reliability of the stated features. Interestingly, the work of Yang et al. [28] extended the theory of planned behaviour to measure trustworthiness. However, the present study has not taken the study of Yang et al. to investigate trustworthiness but has stuck with articles that are more closely linked with consumer behaviour related to commodity consumption instead of smart home services.

This study differs from the standard methods used in the literature i.e., Yang et al. [28], Morgan and Hunt [29], and Flavián et al. [30] by taking a different stance.

\subsubsection{Effectiveness}

The customers' satisfaction is driven by the consumption of labelled or advertised products creating positive perception [1]. In this study, effectiveness is determined through the degree to which consumers find that products are successfully able to meet the desired results.

\subsubsection{Awareness}

Awareness is adequate information about the products or services among consumers [1]. In this study, awareness is the knowledge about the products among consumers, which shapes their perception in a certain manner. Awareness affects the behaviour of consumers in a significant manner [28,29]. For instance, business image is humanized through ethical labelling, which creates awareness among consumers. The ethical qualities of a product also play a positive role in developing trust among consumers, showing that the product is ethical and sustainable [28]. The decision and behaviour of consumers are affected mainly by knowledge, trust, and awareness [30]. Knowledge, trust, and awareness are critical psychological features and traits of consumers, explaining their behaviours. 
Furthermore, awareness and trust are essential features that are visible in human automaticity because they consciously or unconsciously demonstrate it in their course of actions [30].

\subsection{Consumer Perception and Green Advertisement}

A plethora of research has focused on greenwashing and green marketing by either exploring consumer skepticism of green advertising [1,3,31] or a label's trustworthiness [32]. Nevertheless, an attempt has been made by considering the consumers' perspective related to greenwashing by exploring the trust aspect [33]. The same study also found, like other studies, that marketing messages are skeptically viewed by the consumers, especially when adverts were 'green', yet, they did not distrust the labels [33]. In other words, consumers have assumed that despite all the advertisement and skepticism, it is vital that the information should have some part of truth to retain their trust. The study has a unique attribute because it attempts to disclose the sin of lying and misrepresentation of businesses, further participants were surprised and shocked when they found that the label was fake and contained no such features that were claimed. On the other hand, a finding of the study revealed that in recent times, consumers have become more skeptical of the labels [34], reflecting the awareness being developed among consumers. However, the other study found that consumers are not too skeptical and lack proper awareness about products and their claims [33]. Furthermore, labels are found to be significantly effective in convincing consumers, even when consumers do understand greenwashing sins [33]. Since, different studies have shown a different set of findings, offering an exciting conflict among researchers, it gives a motivation to build on the subject matter views and further expand the work in the same field using the Affect-Reason-Involvement (ARI) model. However, before ARI model justification, the next logical step is to explore the consumers' awareness about greenwashing.

A plethora of research has shown that consumers view green advertising with skepticism, which has driven this research to investigate "Whether global consumers are able to identify and differentiate between sustainable and greenwashed products or not"? Studies showed that consumers are unable to identify greenwashed advertisements as deceptive [10,35]. Often when environmentally neutral adverts or greenwashed adverts are presented to consumers, they would view brands as being more environmentally friendly even if they were greenwashed [35]. It is also assumed that despite being sceptical about greenwashing, consumers still consider greenwashed adverts as being more environmentally friendly [1]. Nevertheless, study findings revealed that "consumer's attitudes toward greenwashed adverts were not any more favourable than their attitudes toward adverts without greenwashing; thus, they could not conclude that a more favourable attitude could be gained from the use of greenwashing" [35]. Thus, it indirectly reflects that consumers' awareness regarding greenwashing is rather limited. Furthermore, the same study found that after exposure to a greenwashed advertisement, the chances are likely that consumers would buy a product more often [35]. Interestingly, there is also a study that confirmed that there is no correlation between environmental concern and ability to identify misleading environmental adverts [10]. It is also interesting as it conveys the viewpoint that it is not necessarily correct that environmentalists having a theoretical knowledge might not be able to recognize greenwashed advertisements. There are High, Low, and Moderate environmentalists but yet no study is available that shows the magnitude of the impact of greenwashing on them being different or the same. Additionally, there are also indications that consumers who viewed themselves as environmentally friendly had a relatively lower concern of such adverts, reflecting that they do not evaluate claims in- depth like they should [36]. It may reflect that more than a simple concern for the environment is required as there should be initiative rather than merely caring while unable to identify the misleading adverts. There is a need for organisations to increase more consumer awareness regarding what the deceptive and misleading environmental advertisements look like.

It is interesting as both studies found that only a negative attitude is shown when deception is found by consumers. One study found a negative attitude towards the brand as well as green 
advertising when deceptions in the adverts were identified [35]. Whereas, the other study found that if there is no deception then their attitude will be positive towards green advertising [36]. It could be argued that consumers are in ignorance unless they visibly notice the deception. Nonetheless, it has become visible that being skeptical or being aware are two distinctive things. It becomes difficult for organisations to get away with greenwashing once consumers are aware of it, while the phenomenon will work if the consumers are only skeptical [1]. Here, the logical question arises why would companies still opt for it? Having said that, a recent study has concluded that greenwashing is not effectively a beneficial strategy because it does not affect the consumers' purchase intent [37]. The purchases of consumers increase only when the companies demonstrate a real and genuine interest in the protection of the environment [37]. The same study also found that "greenwashing has a positive effect on the perceived environmental performance of the organization, but a negative effect on the perceived integrity of its communication" [37]. It reflects that the area is still under research as there is still no conformity about understanding how consumers in actuality react to environmental adverts and their respective labelling. Since an earlier study showed perceived aspects, the question arises how consumers react to environmental adverts and their labelling, when they have experienced it in actuality. So far, the positive effect reaction on the perceived environmental performance of the organization and negatively perceived integrity of communication have been confirmed. These positive and negative reactions are based on perception while the actual reaction; irrespective of nature is still under research. As this study focused on labelling but in the due process considered advertisement-because labelling is the widely used component of greenwashing and it is promoted through advertisement-it is necessary to briefly explain advertisement. Hence, both appear to be in parallel, but they are interlinked, and researchers have studied the aspects of labelling through advertisement to some extent so that there is clear visibility. Again, this study offers scope by considering the limitation of earlier research that focused on perception-based positive and negative reactions related to adverts and labelling. This study then takes it a step further by exploring the actual reactions. The prime focus remains on labelling whereas advertisement is explained to some extent in order to ensure it is not discarded completely, because at times they are interlinked.

\subsection{ARI Model}

Researchers have increased efforts in recent times to examine the greenwashing effects on the consumers' perception yet lack theoretical approach to examine the mechanisms and conditions of the effect of misleading advertising on consumers' trust, awareness, and effectiveness. Hence, to address the gap in the existing literature, this study adopts the Affect-Reason-Involvement (ARI) model that has been already used in the study of Schmuk et al. [3]. The authors of the present study developed and tested the theoretical model in three economies, namely Canada, Pakistan, and the UK. The cross-national approach was used to examine the consumers' perception regarding greenwashing in different cultural and marketing contexts. "The key features of advertising messages and consumers along with their interaction effects are part of theory-driven model of greenwashing effects, which enable us to explain the rational and affective mechanisms of greenwashing effects" [3]. Rational cognition and effect are the two qualitative distinctive yet concurrent persuasive mechanisms that lead to formulating attitude are the main postulates of the ARI model [38,39]. Dependent upon the features of the messages to which consumers are often open, the formulation of an attitude is grounded on a positive impact of effect, a positive impact of rational cognition, or the impact of both mechanisms simultaneously [3]. The ARI model makes an assumption that the quality and depth of consumers' response towards advertisement is moderated by involvement of the consumers and hence they continue to interact with the advertising messages. This reflects that the ARI model is similar to dual-process models, such as the Heuristic-Systematic Model (HSM) [40], and the Elaboration Likelihood Model (ELM) [41]. In fact, the ARI model differentiates two distinctive types of persuasion mechanism on conceptual grounds. Nonetheless, all dual-process models treat attitude formation on peripheral or central persuasion, in the same way; affective and rational persuasion influences are core postulates of the ARI model 
on the formation of attitude occurring interactively and simultaneously [3]. Moreover, "dual-process models such as ELM and HSM considered peripheral mechanisms as inferior to systematic cognitive persuasion" [41] while "the ARI model views the emotions' subjective experience, or affect or effect, as a type of cognition - specifically, as a type of knowledge-which is not inferior to rational cognition. By extension, if emotional persuasion is based on holistic syncretic cognition, then rational persuasion is based on linear and sequential analytic cognition" [41]. That consideration serves as the basis to describe the messages of greenwashing and its impact on the perception, trust, effectiveness, and awareness of the consumers.

Lastly, the literature at hand has indirectly confirmed the negative impact of greenwashed products but it is not conclusive if the companies' greenwashed products negatively affect their own consumers' green purchase behaviour. In other words, in order to improve a company's image and profit margins, the false claim of being involved in green activities, if it is found by the consumers will negatively affect the green purchase behaviour of consumers. A study has shown that companies that exaggerate ample claims about their practices would lead to consumers not trusting them [35]. Hence, it could be said that the reputation and image of the firms would be more damaged if they adopted greenwashing techniques. "If firms use green-wash activities to deceive customers, in order that they will not purchase their product any longer, as a result of that they may increase their negative perception regarding the firm and its product" [42]. Going further, there is a possibility that perhaps it might generate negative verbal publicity about the products and companies. Greenwash tends to exaggerate the purchase behaviour of consumers. Often when companies use greenwash practices, then such practices negatively affect the consumers' purchase [43]. Hence, if companies use genuine green practices with no intent to deceive consumers, then positive purchase behaviour will be the result. "Greenwash practices also harm customer's attitudes toward buying their products or services" [44]. The firms which truly adopt green marketing activities and the firms who are not deceiving customers and who are really trying to make the environment healthy, would also be perceived as unfavourable because of the perception that has been developed in customers' minds about the overall general practices of the firm's greenwash activities [44,45]. Therefore, it could be concluded that the companies invest in green marketing and green advertising to eliminate negative word-of-mouth publicity and to transform the consumers' negative perception into positive perception about products and companies at large. Perhaps, the company's sincere efforts and investment in green marketing activities would be useful in creating positive buying behaviours of global consumers.

Previous empirical studies highlighted the need for investigation about the perception of consumers on greenwashing $[1,3,11,20,31,33,45]$. Despite a plethora of research, some studies reported consumers being highly skeptical of greenwashing and companies that claim but do not use it, were found to affect the company's success plans $[11,20,31]$. Whereas, other studies reported that greenwashing works, as those studies concluded that consumers still see some aspect of the truth and thought that some companies are more environmentally conscious on some aspects of green labels $[10,33]$. Interestingly, there is a piece of evidence that consumers are more inclined to buy products after being exposed to greenwashed adverts [35]. Thus, there is a need for further investigation to explore the understanding of consumers regarding greenwashing. Notably, the use of the ARI model is to examine the awareness, trust, and effectiveness from a global perspective. There have been attempts made by researchers, such as one study which examined the consumers' perception related to greenwashing [1], but it is mostly region-specific and therefore, does not offer cross-cultural information to give a broader generalization. Furthermore, the study, despite claiming quantitative analysis, has largely used single variate, reflecting more qualitative aspects than quantitative ones. In fact, the mathematical objectivity to have factual truth is limited while useful truth goes beyond numeric expression in understanding the embedded hidden aspects which are not explored. Similarly, another study attempted to use the ARI model [3], but mainly focused on green advertising's impact rather than exploring the perception of consumers. 


\subsection{ARI Model Integration in Theoretical Underpinning}

The work of Schmuk et al. [3] is partially adopted to investigate the perception of consumers and further extended to measure consumers green behaviour. The attributes of greenwashing identified by Schmuk et al. [3] under the ARI-model is adopted along with the environmentalists. However, the environmentalists are further categorized through degree and the work of Halverson [1] is incorporated to assess the components of consumers' perception. Moreover, the work of Chang [18] is considered by investigating green purchase behaviour. All the constructs are taken into consideration to extend existing knowledge by attaining a global perspective.

There are traces of consumers perception studied in the context of labelling of consumer behaviour in the context of green advertisement. However, labelling is part of greenwashing, which also falls under green advertisement. Therefore, there is indirect evidence which still needs investigation of consumers' green behaviour affected by greenwashing. Again, Schmuk et al. [3] only studied vagueness and false labelling with a focus on trust, whereas the sin of irrelevant labelling affecting effectiveness and awareness is still under research. (Figure 1).

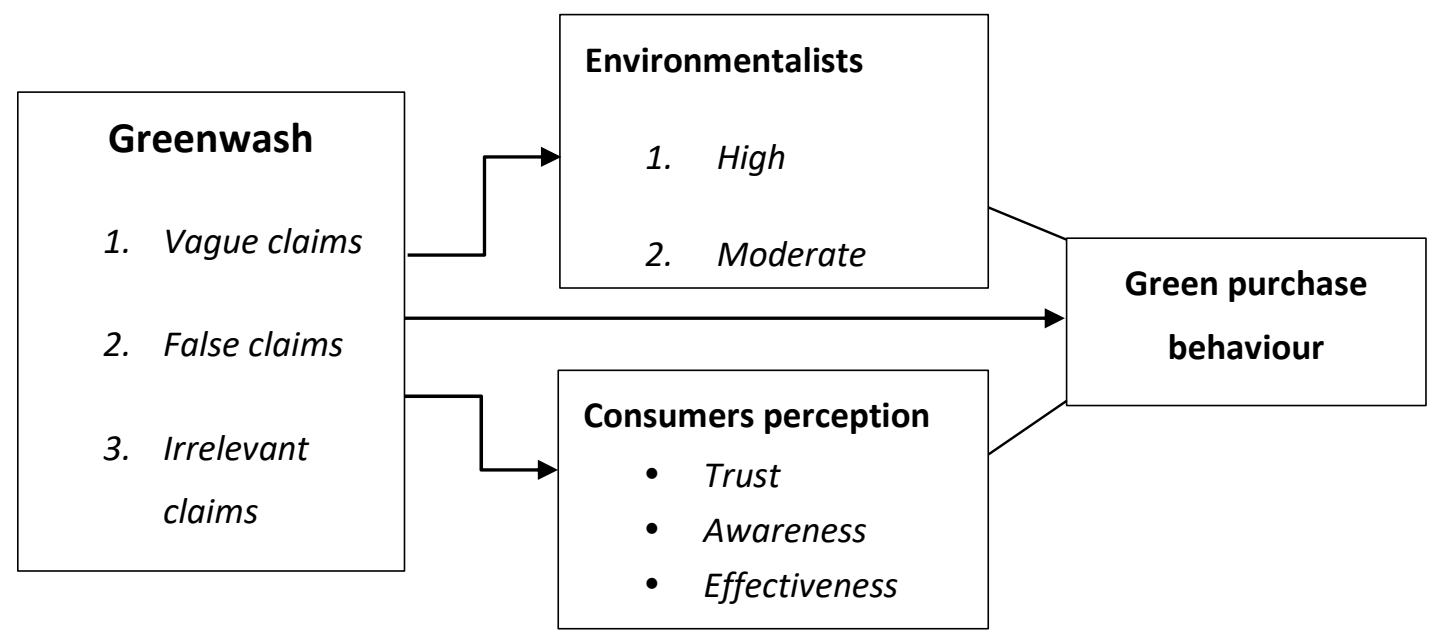

Figure 1. Conceptual model of the present study.

Thus, this study takes further initiative to investigate the consumers' perception in the global context using the ARI model.

\subsection{Research Hypotheses}

Therefore, based on the above discussion, the following hypotheses are generated:

Hypothesis 1: Higher degree of environmentalists is more skeptical than the others (low and moderate environmentalists) in identifying greenwashed products as non-sustainable.

Hypothesis 2: Higher degree of green purchasing behaviour in comparison to the others (low and moderate green purchasing behaviour) has a higher tendency to restrain from using greenwashing products.

Hypothesis 3: False label does not affect the consumers' perception.

Hypothesis 4: Irrelevant label does not affect the consumers' perception.

Hypothesis 5: Vague label does not affect consumers' perception.

Hypothesis 6: Greenwashing does not affect the purchase intent of the consumers. 
Hypothesis 7: Greenwashing does not affect the green purchase behaviour negatively.

\section{Research Methodology}

This cross-sectional study works on the proposed ARI model [3] while primarily adopting Halverson's strategy to investigate the perception of consumers regarding greenwashing [1]. Generic products are commonly used by males and females while ensuring that the products could have green alternatives. Greenwashed products related attributes such as vagueness, false labels, and irrelevance are tested [45]. The green purchase behaviour questions were adopted from earlier work [18]. As a part of the study, the image of one item was without any label in order to have a controlled aspect within the study, while another three images on the item displayed, falseness, vagueness, advert irrelevance, following the strategy of earlier studies [1,45]. The item contained a false claim to be "Certified Green Environmentally Conscious" while it was not true. The item reflected vagueness by giving a generic recycling label with no additional information, whereas the third item had irrelevance aspects that were not linked with the actual item inside. Building on the content and work of earlier studies, i.e., $[1,18,45]$, the researchers developed a questionnaire, which also reflected the content validity and reliability.

Along with the survey, the respondents were given a consent form to ensure they willingly participated in this study by filling in honestly the demographic questions along with various questions related to environmental lifestyle and outlook (See Appendix A Table A1). Four groups were formed, and, at the start, participants were asked to choose one packaging item, namely Alpha, Bravo, Charlie, and Delta. Participants picked the item without knowing whether the packaging reflected falseness, vagueness, irrelevance or actual greenness. (a) Alpha group: represented a false label, (b) Bravo group: represented vagueness, (c) Charlie group: represented irrelevance, and (d) Delta group: represented green products. On reaching a certain quota in one group, it was then excluded from the survey set while others were given to participants to select from. The process proved lengthy but effective in ensuring all four groups had equal representation in the study. The questions included aspects related to attractiveness, sustainability, information, quality, trustworthiness, and the appeal of a product of being green and environmentally friendly affecting purchase intent. All four groups were later asked about how they viewed greenness, whether the label has or has not functioned as environmentally friendly, affecting their purchase intent.

Later all groups were given the description of greenwashing in general and the magnitude of the survey was such that the awareness could be tested. It was followed by questions related to the packaging they identified to see how they believed its greenwashing and debriefing them of the message of the item helped them identify how aware they were about various types of greenwashing.

Using Leblanc's marginal error formula, the study found that 200 is a minimum sample size in a region. Within the scientific research, "margin of error" of \pm 3 is allowed only if there is a control overconfidence level and sample size [46]. To a greater degree, the parameter of population $(P)$ affecting the value of prior judgement value $\left(\hat{p}^{\prime}\right)$ could not be controlled. Thus, the M.E Margin of Error formula is effective to attain the probable estimation of the population to draw sample size (M.E = $z \sqrt{\hat{\mathbf{p}}(1-\hat{\mathbf{p}})}$ [8]. In social science research, up to \pm 4 could be used [47]. This is social science research using a scientific approach, therefore, the margin of error is \pm 4 , which means 0.04 for measuring the sample size with $z=1.96$ for $95 \%$ confidence interval, $\hat{\mathbf{p}}=$ prior judgement of the correct value of $p$ is estimated 0.1 . Since there is no sample framework therefore, we assume $10 \%$ to be the minimum targeted population in the targeted region.

$$
\text { M.E }=\frac{z \sqrt{\hat{\mathbf{p}}(1-\hat{\mathbf{p}})}}{\mathbf{n}}
$$

$z=1.96$ with $95 \%$ confidence 
M.E $= \pm 4 \%(0.04)$

$\mathbf{n}=$ Sample Size

$\hat{\mathbf{p}}=$ prior judgement of the correct value of $p$ (Probability to have more than $10 \%$ of population)

$$
\begin{gathered}
\text { M.E }=\frac{z \sqrt{\hat{\mathbf{p}}(1-\hat{\mathbf{p}})}}{\mathbf{n}} \\
\mathbf{n}=\frac{z \sqrt{\hat{\mathbf{p}}(1-\hat{\mathbf{p}})}}{\mathrm{M} . \mathrm{E}} \\
\mathbf{n}=\frac{\hat{\mathbf{p}}(1-\mathbf{p}) z^{2}}{\mathrm{M} \cdot \mathrm{E}^{2}} \\
\mathbf{n}=\frac{0.1(1-0.1)(1.96)^{2}}{(0.04)^{2}} \\
\mathbf{n}=\frac{(0.1 \times 0.9) \times(1.96 \times 1.96)}{0.04 \times 0.04} \\
\mathbf{n}=\frac{0.09 \times 3.8414}{0.0016} \\
\mathbf{n}=\frac{0.34324}{0.0016} \\
\mathbf{n}=214.53
\end{gathered}
$$

Thus, by using this formula, the minimum sample required is 215 , so the study ensured more responses were attained than the derived value. A stratum was formed by ensuring that at least over 215 was attained each from all considered countries (strata). The stratum was used for case location so that there was equal representation in both countries. Hence, the strata were formed but the collection of the survey from the participants was done through convenient sampling strategy. In other words, the strata were formed to identify the representative sample while convenience sampling was used for gathering data from the respondents. The number of studies concluded that over 200 is a sufficient sample size to draw a logical conclusion [49]. In the cross-sectional comparative studies, there is a pattern to ensure fair representation is made about distinctive regions in order to have broader generalization as well as a logical conclusion [50-53]. Since the research focuses on the attainment of a global perspective, consumers from the UK, Canada, and Pakistan were targeted. A plethora of research has confirmed that a comparative strategy is effective in attaining global perspective; Haque Nair Kuckultan [51], Haque et al. [53], Kot et al. [50], and Kot et al. [54]. Hence, the authors employed the same comparative strategy to attain a global perspective. For equal and fair representation in all selected regions, the authors used the convenience and purposive sampling technique because it is effective when the randomization of the sample is impractical and costly when the sampling framework is missing so the intention was to have a fair representation of the sample in the region. As a result, eventually, the study reached a total of 768 (256 each in the UK, Canada, and Pakistan). The authors used manual circulation of the survey among respondents; therefore, the second lead researcher travelled to all three regions with the packaging materials in all three countries and personally conducted the survey. The connections and referrals were used to attain the consent of different authorities to commence a survey.

The use of the existing survey instrument was to ensure the content and face-value validity and reliability of the instrument. Nevertheless, it was further checked by using a statistical tool to ensure that internal and external validity was further obtained because, in the case of using the nonprobability sampling technique, there is a chance of validity issues. Hence, it is an effective method to ensure validity from internal as well as external aspects. 
For data analysis, the researchers used the Chi-Square test for ranked data namely, environmentalists and green purchasers while for the degree-based responses, smartPLS 3.2.8 software was employed to validate the partial least square structural equation modeling (PLS-SEM) [55]. "The PLS-SEM was evaluated into a two-step approach such as the measurement model and structural model" [56]. The reason for preferring the Chi-Square test is because the questionnaire was designed with the intent to rank the degree of environmentalists by means of categorizing them as higher, moderate, and lower ones. Though, it is a debatable approach as respondents have categorized themselves, it could be possible that it is rather more perception reported than actuality. Nevertheless, social sciences studies hold always a subjective view. Following the strategy of Pallant [57], the authors employed a rank scale by asking participants to select the option of how they see themselves. Thus, it could be more of perception rather than actuality, but there is no certain way in any scale to know for sure if respondents are actually stating reality or mere perception.

\section{Results and Findings}

\subsection{Measurement Model}

Measurement model used to test the scale reliability and validity. Cronbach alpha and composite reliability criteria models were used to evaluate the reliability. The greater value or equal to 0.7 for Cronbach's alpha and composite reliability is acceptable in social science studies [51]. Furthermore, Average Variance Extracted (AVE) obtained values greater than 0.5 reflects the validity of the scale's internal consistency [52]. In the present study, all three criteria were found to be acceptable as Cronbach alpha and composite reliability were greater than 0.7 while AVE was greater than 0.5 in all three countries (Table 1, Figures 2-4).

Table 1. Reliability and validity.

\begin{tabular}{cccc}
\hline Constructs & Cronbach's Alpha & $\begin{array}{c}\text { Composite Reliability } \\
\text { United Kingdom }\end{array}$ & Average Variance Extracted (AVE) \\
\hline Consumer perception & 0.782 & 0.836 & 0.564 \\
Trust & 0.761 & 0.771 & 0.624 \\
Awareness & 0.735 & 0.764 & 0.654 \\
Effectiveness & 0.724 & 0.714 & 0.583 \\
Greenwash & 0.713 & 0.701 & 0.591 \\
Purchase behaviour & 0.705 & 0.722 & 0.627 \\
\hline & & & \\
Consumer perception & 0.755 & 0.763 & 0.567 \\
Trust & 0.749 & 0.719 & 0.551 \\
Awareness & 0.875 & 0.742 & 0.547 \\
Effectiveness & 0.771 & 0.783 & 0.529 \\
Greenwash & 0.703 & 0.714 & 0.661 \\
Purchase behaviour & 0.769 & 0.722 & 0.649 \\
\hline & & & \\
\hline Consumer perception & 0.767 & Pakistan & 0.674 \\
Trust & 0.743 & 0.836 & 0.533 \\
Awareness & 0.799 & 0.771 & 0.545 \\
Effectiveness & 0.828 & 0.764 & 0.532 \\
Greenwash & 0.738 & 0.714 & 0.517 \\
Purchase behaviour & 0.752 & 0.701 & 0.545 \\
\hline
\end{tabular}

To measure the external validity, the latest criteria Heterotrait-Monotrait ratio of correlations (HTMT) was used to examine the discriminant validity [56]. The reason for preferring HTMT than Fornell and Larcker Criteria is because the latter is subject to biases when the sampling is not randomized, whereas HTMT is more accurate in determining the external discriminant validity. “The latent variables' AVEs being greater than the square root average variance extracted, indicate 
valid results" [49]. In this study, all the obtained values are valid. The values of HTMT less than 1 reflect the constructs that have acceptable external validity [52,53,55]. Nunally [58] argued that the loading items should be above 0.7. Nevertheless, according to Hamid et al. [59], "Fornell and Larcker criterion and the assessment of the cross-loadings are inadequately sensitive in detecting discriminant validity when compared with Heterotrait-Monotrait (HTMT) criterion. Thus, the use of HTMT criterion has to be adopted for this purpose so that the interpretation of the causal effect in the modelling analysis is not misleading. Despite its strictest procedure (HTMT compared to Fornell and Larcker criterion), the measurement model would be free from any problems besides creating a good quality measurement tool through the items in the developed questionnaire". Hence, the study considered the Hamid et al. [58] argument and used HTMT for discriminant validity. In the present study, the obtained valued for the all the constructs in all three countries under HTMT test were found to be less than 1, which reflects that there is acceptable external discriminant validity (Table 2; Table 3).

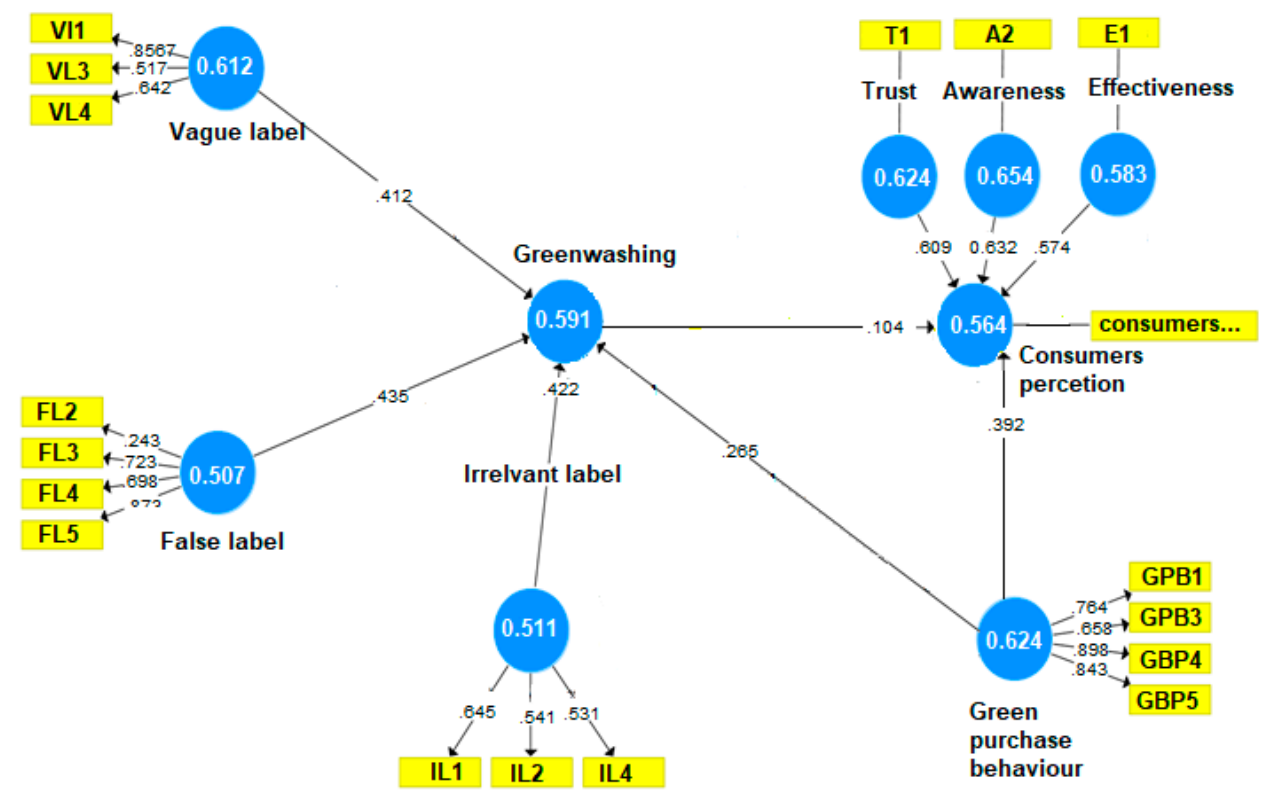

Figure 2. Constructs' discriminant validity in the UK.

Table 2. Discriminant validity (Fornell-Larcker criterion).

\begin{tabular}{|c|c|c|c|c|c|c|}
\hline Constructs & Consumer Perception & Trust & Awareness & Effectiveness & Greenwash & Purchase Behaviour \\
\hline \multicolumn{7}{|c|}{ United Kingdom } \\
\hline Consumer perception & 0.621 & & & & & \\
\hline Trust & 0.601 & 0.911 & & & & \\
\hline Awareness & 0.597 & 0.857 & 0.982 & & & \\
\hline Effectiveness & 0.555 & 0.711 & 0.763 & 0.758 & & \\
\hline Greenwash & 0.541 & 0.672 & 0.722 & 0.721 & 0.719 & \\
\hline Purchase behaviour & 0.502 & 0.613 & 0.707 & 0.637 & 0.632 & 0.599 \\
\hline \multicolumn{7}{|c|}{ Canada } \\
\hline Consumer perception & 0.618 & & & & & \\
\hline Trust & 0.632 & 0.906 & & & & \\
\hline Awareness & 0.568 & 0.841 & 0.901 & & & \\
\hline Effectiveness & 0.512 & 0.763 & 0.759 & 0.751 & & \\
\hline Greenwash & 0.533 & 0.666 & 0.747 & 0.719 & 0.704 & \\
\hline Purchase behaviour & 0.571 & 0.612 & 0.689 & 0.622 & 0.618 & 0.583 \\
\hline \multicolumn{7}{|c|}{ Pakistan } \\
\hline Consumer perception & 0.605 & & & & & \\
\hline Trust & 0.557 & 0.812 & & & & \\
\hline Awareness & 0.512 & 0.733 & 0.863 & & & \\
\hline Effectiveness & 0.509 & 0.719 & 0.751 & 0.723 & & \\
\hline Greenwash & 0.532 & 0.611 & 0.634 & 0.651 & 0.701 & \\
\hline Purchase behaviour & 0.501 & 0.601 & 0.621 & 0.612 & 0.611 & 0.575 \\
\hline
\end{tabular}




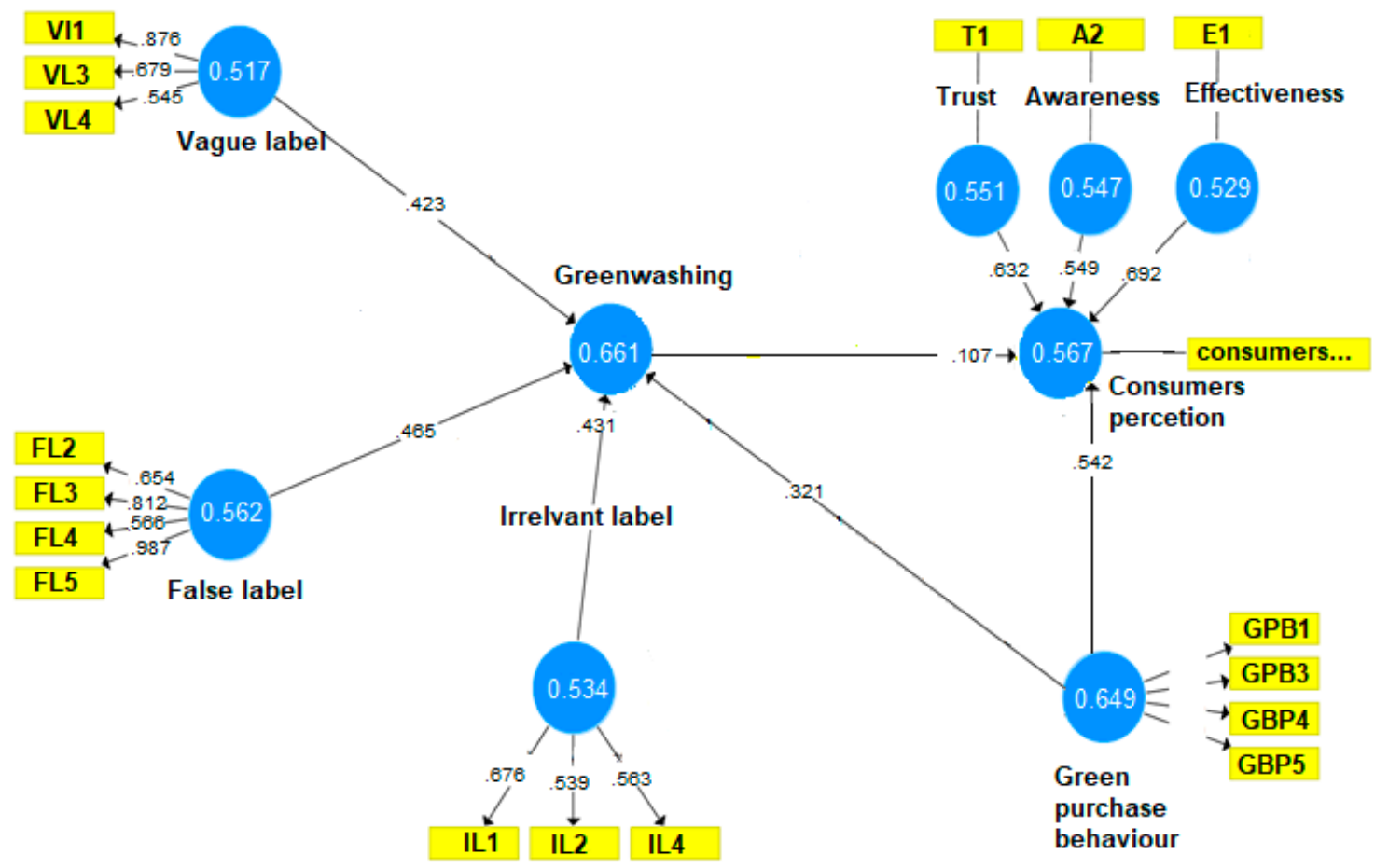

Figure 3. Constructs' discriminant validity in Canada.

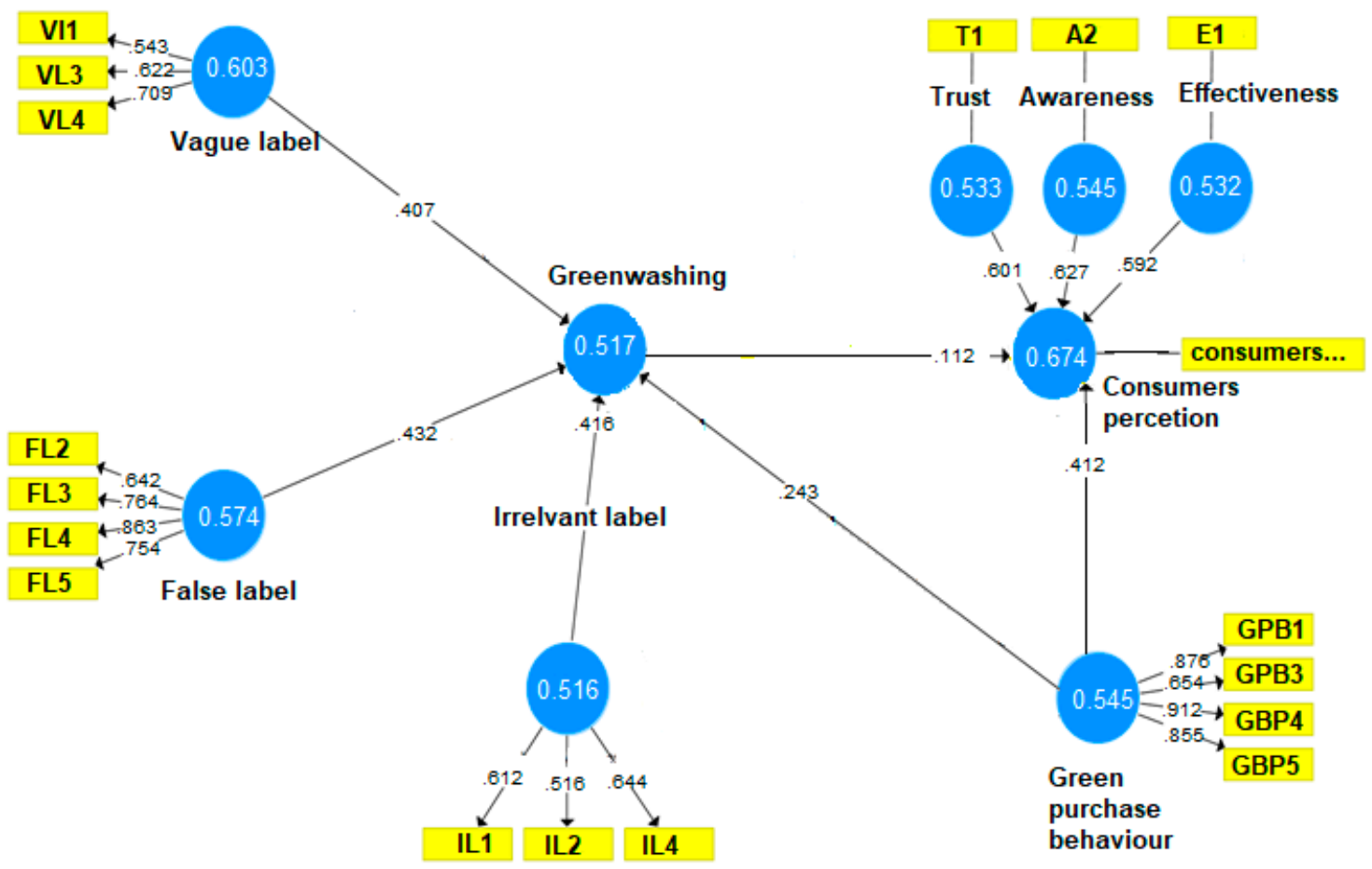

Figure 4. Constructs' discriminant validity in Pakistan. 
Table 3. Heterotrait-Monotrait (HTMT) ratio of correlations.

\begin{tabular}{|c|c|c|c|c|c|c|}
\hline Constructs & Consumer Perception & Trust & Awareness & Effectiveness & Greenwash & Purchase Behaviour \\
\hline \multicolumn{7}{|c|}{ United Kingdom } \\
\hline Consumer perception & 0.543 & & & & & \\
\hline Trust & 0.535 & 0.891 & & & & \\
\hline Awareness & 0.471 & 0.744 & 0.876 & & & \\
\hline Effectiveness & 0.334 & 0.723 & 0.541 & 0.675 & & \\
\hline Greenwash & 0.436 & 0.602 & 0.663 & 0.515 & 0.368 & \\
\hline Purchase behaviour & 0.542 & 0.741 & 0.712 & 0.473 & 0.457 & 0.545 \\
\hline \multicolumn{7}{|c|}{ Canada } \\
\hline Consumer perception & 0.766 & & & & & \\
\hline Trust & 0.832 & 0.712 & & & & \\
\hline Awareness & 0.566 & 0.454 & 0.768 & & & \\
\hline Effectiveness & 0.552 & 0.631 & 0.518 & 0.725 & & \\
\hline Greenwash & 0.561 & 0.556 & 0.885 & 0.655 & 0.582 & \\
\hline Purchase behaviour & 0.627 & 0.573 & 0.628 & 0.637 & 0.446 & 0.576 \\
\hline \multicolumn{7}{|c|}{ Pakistan } \\
\hline Consumer perception & 0.423 & & & & & \\
\hline Trust & 0.355 & 0.891 & & & & \\
\hline Awareness & 0.712 & 0.744 & 0.631 & & & \\
\hline Effectiveness & 0.654 & 0.723 & 0.514 & 0.572 & & \\
\hline Greenwash & 0.567 & 0.602 & 0.334 & 0.552 & 0.387 & \\
\hline Purchase behaviour & 0.524 & 0.741 & 0.728 & 0.436 & 0.742 & 0.654 \\
\hline
\end{tabular}

\subsection{Descriptive Statistics}

Since the measurement model confirmed that the scale had met the acceptable criteria of reliability and validity, the researchers continued with the analysis by first exploring the demographic variables through descriptive statistics.

The descriptive statistics revealed that the majority of the participants in this study are females (50.4\%), in the age bracket from (36-45) (36.9\%), with a bachelor's degree (36.8\%) (Table 4). Nevertheless, in a comparative aspect, it was found that the females in this study were mostly from the UK $(63.2 \%)$ while males mostly from Pakistan (71.4\%) (Table 4). In all three countries, the majority of the respondents are from 36-45 (UK: $40.2 \%$, CAN: $33.2 \%$, and PAK: 37.5 ; Table 3). Similarly, in all three countries, the majority of the respondents hold a bachelor's degree (UK: $38.6 \%$, CAN: $28.9 \%$, and PAK: 33.9; Table 4). This reflects that the respondents of the study are mostly mature and have knowledge regarding greenwashing. Further, to confirm, they were given material on greenwashing to ensure they had pertinent information about the research variables.

The next attempt in the questionnaire was to find how the individuals ranked themselves in terms of environmentalists and how they perceived themselves as green purchasers. Interestingly, results revealed that the majority of the participants viewed themselves as moderate environmentalists $(38.2 \%)$, followed by low environmentalists (33.9) and high environmentalists (27.9\%) (Table 5). However, high-level environmentalists were more in Canada while moderate level environmentalists were in the UK and Pakistan. Furthermore, the majority of the participants identified themselves as moderate green purchasers $(38.9 \%)$, followed by high green purchasers (31.5\%), and low green purchasers $(29.6 \%)$ (Table 5). This categorization was made to ensure how ranked environmentalists view greenwashing products as sustainable. The next step was to test the ranked data in the country's context. (Table 6)

The expected count of less than $20 \%$ means the Pearson Chi-Square was to be used for testing the hypothesis [57]. The expected count values were in the assumption range, and there the authors employed Pearson rather than Likelihood Ratio (0.0\% expected count for less than 5; Table 7). The Pearson Chi-square sig value is less than alpha $(=0.003<0.05, p<\alpha)$, reflected that results are statistically significant. In other words, the study rejects the null hypothesis that the higher degree of environmentalist is more skeptical than the others (low and moderate environmentalists) in identifying greenwashed products as non-sustainable. Significant results mean that there is statistically no difference in the ability to identify greenwashing products among high, moderate, and low environmentalists. Symmetric Measures have two criteria, 2 rows 2 columns Phi Value while 2 or more 
rows with 3 columns mean Cramer's $V$ is to be used to determine the size effect [57]. Therefore, the study considered Cramer's V, and the results showed that environmentalists in all considered economies have a small to moderate effect on greenwashing identification (Cramer's V: $0.352,0.032<0.05 ; p<\alpha$; Table 8). Interestingly, the funnel approach, previously used by researchers [52-54,60], found that high environmentalists despite their claim for being highly skeptical, most frequently fall into the trap of identifying greenwashing products as sustainable. Using the same approach, the present study found that young consumers have less trust and find greenwashing problematic in comparison to older people. (Table 9).

Table 4. Demographic information of the participants in the study.

\begin{tabular}{|c|c|c|c|c|c|}
\hline \multicolumn{6}{|c|}{ Demographic Information } \\
\hline & & UK (\%) & CAN (\%) & РАK (\%) & TOTAL \\
\hline Male & \multirow[b]{2}{*}{ Gender } & 36.7 & 59.3 & 71.4 & 49.6 \\
\hline Female & & 63.2 & 40.7 & 28.6 & 50.4 \\
\hline $18-25$ & \multirow{5}{*}{ Age } & 21.4 & 16.0 & 26.1 & 21.2 \\
\hline $26-35$ & & 26.9 & 31.2 & 29.2 & 29.1 \\
\hline $36-45$ & & 40.2 & 33.2 & 37.5 & 36.9 \\
\hline 46-55 & & 7.8 & 5.8 & 2.3 & 5.3 \\
\hline 56 or Above & & 3.7 & 13.8 & 4.9 & 7.5 \\
\hline Initial Schooling/O Level & \multirow{6}{*}{ Education } & 16.4 & 12.8 & 12.5 & 13.9 \\
\hline College/A Level & & 31.4 & 28.9 & 25.6 & 28.7 \\
\hline Bachelor's degree & & 38.6 & 37.5 & 33.9 & 36.8 \\
\hline Master's degree & & 12.5 & 16.2 & 26.9 & 18.3 \\
\hline \multirow[t]{2}{*}{ Other } & & 1.1 & 4.6 & 1.1 & 2.3 \\
\hline & & 100 & 100 & 100 & 100 \\
\hline
\end{tabular}

Table 5. Ranked environmentalists and green purchasers.

\begin{tabular}{cccccc}
\hline \multicolumn{5}{c}{ Identifying Oneself } \\
\hline & UK (\%) & CAN (\%) & PAK (\%) & TOTAL \\
\hline High & \multirow{2}{*}{ Environmentalists } & 23.1 & 38.2 & 22.3 & 27.9 \\
Moderate & 41.4 & 33.6 & 39.5 & 38.2 \\
Low & & 35.5 & 28.2 & 38.2 & 33.9 \\
& & 100 & 100 & 100 & 100 \\
\hline High & \multirow{2}{*}{ Green Purchaser } & 33.3 & 38.6 & 27.3 & 31.5 \\
Moderate & 38.2 & 25.5 & 39.4 & 38.9 \\
Low & & 100 & 100 & 100 & 29.6 \\
& & & & & 100 \\
\hline
\end{tabular}

Table 6. Environmentalists identifying greenwashing products as sustainable.

\begin{tabular}{|c|c|c|c|c|c|c|}
\hline & & & \multicolumn{3}{|c|}{ Identifying Greenwashed Products as Sustainable } & \multirow[b]{2}{*}{ Total } \\
\hline & & & $\begin{array}{c}\text { High } \\
\text { Environmentalist }\end{array}$ & $\begin{array}{c}\text { Moderate } \\
\text { Environmentalist }\end{array}$ & $\begin{array}{c}\text { High } \\
\text { Environmentalist }\end{array}$ & \\
\hline \multirow{6}{*}{ Country } & \multirow{2}{*}{ United Kingdom } & Count & 59 & 106 & 91 & 256 \\
\hline & & $\begin{array}{c}\text { Expected } \\
\text { Count }\end{array}$ & 69.5 & 93.5 & 93.0 & 256 \\
\hline & \multirow{2}{*}{ Canada } & Count & 98 & 86 & 72 & 256 \\
\hline & & $\begin{array}{c}\text { Expected } \\
\text { Count }\end{array}$ & 109.5 & 97 & 49.5 & 256 \\
\hline & \multirow[b]{2}{*}{ Pakistan } & Count & 57 & 72 & 98 & 256 \\
\hline & & $\begin{array}{c}\text { Expected } \\
\text { Count }\end{array}$ & 66 & 81 & 109 & 256 \\
\hline
\end{tabular}


Table 7. Chi-Square Tests.

\begin{tabular}{cccc}
\hline & Value & Df & Asymp. Sig. (2-Sided) \\
\hline Pearson Chi-Square & 6.395 & 3 & 0.031 \\
Likelihood Ratio & 6.247 & 3 & 0.042 \\
Linear-by-Linear Association & 0.521 & 2 & 0.502 \\
N of Valid Cases & 768 & & \\
\hline
\end{tabular}

Notes: a. 0 cells $(0.0 \%)$ have expected count less than 5 . The minimum expected count is 33.00 .

Table 8. Symmetric measures.

\begin{tabular}{cccc}
\hline & & Value & Approx. Sig. \\
\hline \multirow{2}{*}{ Nominal by Nominal } & Phi & 0.361 & 0.031 \\
\multicolumn{2}{c}{ N of Valid Cases } & 0.362 & 0.032 \\
\hline
\end{tabular}

Table 9. Identifying oneself as a green purchaser.

\begin{tabular}{|c|c|c|c|c|c|c|}
\hline & & & \multicolumn{3}{|c|}{ Identifying Oneself as a Green Purchaser } & \multirow{2}{*}{ Total } \\
\hline & & & High & Moderate & High & \\
\hline \multirow{6}{*}{ Country } & \multirow{2}{*}{ United Kingdom } & Count & 73 & 94 & 89 & 256 \\
\hline & & $\begin{array}{c}\text { Expected } \\
\text { Count }\end{array}$ & 81 & 103.5 & 71.5 & 256 \\
\hline & \multirow[b]{2}{*}{ Canada } & Count & 99 & 92 & 65 & 256 \\
\hline & & $\begin{array}{c}\text { Expected } \\
\text { Count }\end{array}$ & 102.5 & 87.5 & 66 & 256 \\
\hline & \multirow[b]{2}{*}{ Pakistan } & Count & 70 & 101 & 85 & 256 \\
\hline & & $\begin{array}{c}\text { Expected } \\
\text { Count }\end{array}$ & 76 & 110 & 70 & 256 \\
\hline
\end{tabular}

Furthermore, the research findings revealed that in all three countries, consumers identify themselves as green purchasers. Again, the expected count assumption is not violated [57]. Thus, the Pearson Chi-Square value is considered over the Likelihood ratio (Table 10). Results are statistically significant $(0.044<0.05 ; p<\alpha$; Table 11). In other words, hypothesis 2 is rejected that individuals viewing themselves as green purchasers to different degrees are unable to restrain from buying greenwashing products. Therefore, it is confirmed that irrespective of considering oneself, in any country, the consumers tend to fall for greenwashing products. Furthermore, Cramer's $\mathrm{V}$ revealed that green purchasers in all considered economies have a small to moderate effect on greenwashing identification (Cramer's V: $0.213, p<\alpha ; 0.044<0.05$; Table 10). Consumers were found to be vulnerable and more sensitive when their attention was drawn towards greenwashing. Using the funnel approach, younger people reported having no or minimal trust while frequently believing greenwashing is problematic, whereas older people easily trust greenwashing as being sustainable. Nevertheless, the overall report has shown that despite still finding it problematic, the majority of the respondents consume greenwashed products.

Table 10. Chi-Square tests.

\begin{tabular}{cccc}
\hline & Value & Df & Asymp. Sig. (2-Sided) \\
\hline Pearson Chi-Square & 5.221 & 3 & 0.044 \\
Likelihood Ratio & 5.124 & 3 & 0.049 \\
Linear-by-Linear Association & 0.532 & 2 & 0.502 \\
N of Valid Cases & 768 & & \\
\hline
\end{tabular}

Notes: a. 0 cells $(0.0 \%)$ have expected count less than 5 . The minimum expected count is 33.00 . 
Table 11. Symmetric measures.

\begin{tabular}{cccc}
\hline & & Value & Approx. Sig. \\
\hline \multirow{2}{*}{ Nominal by Nominal } & Phi & 0.213 & 0.044 \\
N of Valid Cases & 0.224 & 0.049 \\
\hline
\end{tabular}

\subsection{Structural Model}

After the validation of the measurement model and descriptive statistics, the next step in the study was to assess the structural model through the path co-efficient. The bootstrapping option was used to test the statistical significance of the path co-efficient. A t-value of 1.96 at a significant value of 0.05 is a criterion for testing hypotheses in this study. A $t$-value greater than 1.96 or probability value less than 0.05 is statistically significant, reflecting accepted results while vice versa would be non-significant, and therefore, would be rejected. The participants selecting the control package, were not included in a test to measure their trustworthiness because they had already selected the authentic product package.

The results revealed that in all three countries, the consumers' perception is statistically and significantly affected by false labelling (UK: $-\mathrm{t}$-value: 7.37, $p<\alpha ; 0.000<0.05$; CAN: $-\mathrm{t}$-value: 5.07, $p<\alpha ; 0.000<0.05$; PAK: -t-value: $2.96, p<\alpha ; 0.000<0.05$; Table 12). Hence, there is strong evidence in favour of the null hypothesis, and therefore, this study accepts hypothesis 3 . It is found that irrelevant labelling has a statistically significant relation with the consumers' perception (UK: $-\mathrm{t}$-value: 2.818 , $p<\alpha ; 0.005<0.05$; CAN: -t-value: 3.053, $p<\alpha ; 0.002<0.05$; PAK: -t-value: 7.905, $p<\alpha ; 0.000<0.05$; Table 12). With strong evidence in favour of the null hypothesis, the study accepts hypothesis 4 . The findings also revealed that in all three considered countries, the vagueness statistically and significantly affects the consumers' perception (UK: $-\mathrm{t}$-value: $3.306, p<\alpha ; 0.005<0.05$; CAN: $-\mathrm{t}$-value: 6.243, $p<\alpha ; 0.002<0.05$; PAK: $-\mathrm{t}$-value: 9.808, $p<\alpha ; 0.000<0.05$; Table 12). There is strong evidence in favour of the null hypothesis, thus, the study accepts hypothesis 5 . Moreover, the statistical results confirmed that the purchase intent of the consumers is not affected by greenwashing (UK: $-\mathrm{t}$-value: 3.328, $p<\alpha ; 0.000<0.05$; CAN: -t-value: 4.395, $p<\alpha$; $0.000<0.05$; PAK: $-\mathrm{t}$-value: $5.240, p<\alpha$; $0.000<0.05 ;$ Table 12). It, therefore, confirms that from all three considered countries, the purchase intent of the consumers does not vary because of greenwashing. Hence, the study accepts hypothesis 6 . Lastly, the study found that greenwashing negatively affects green purchase behaviour, as the results are non-significant, hence, the authors have strong evidence against the null hypothesis (UK: $-\mathrm{t}$-value: 1.495, $p>\alpha$; $0.652>0.05$; CAN: -t-value: 1.701, $p>\alpha$; $0.317>0.05$; PAK: -t-value: $1.615, p>\alpha$; $0.208>0.05$; Table 12). Thus, it rejects hypothesis 7 .

Table 12. Structural model.

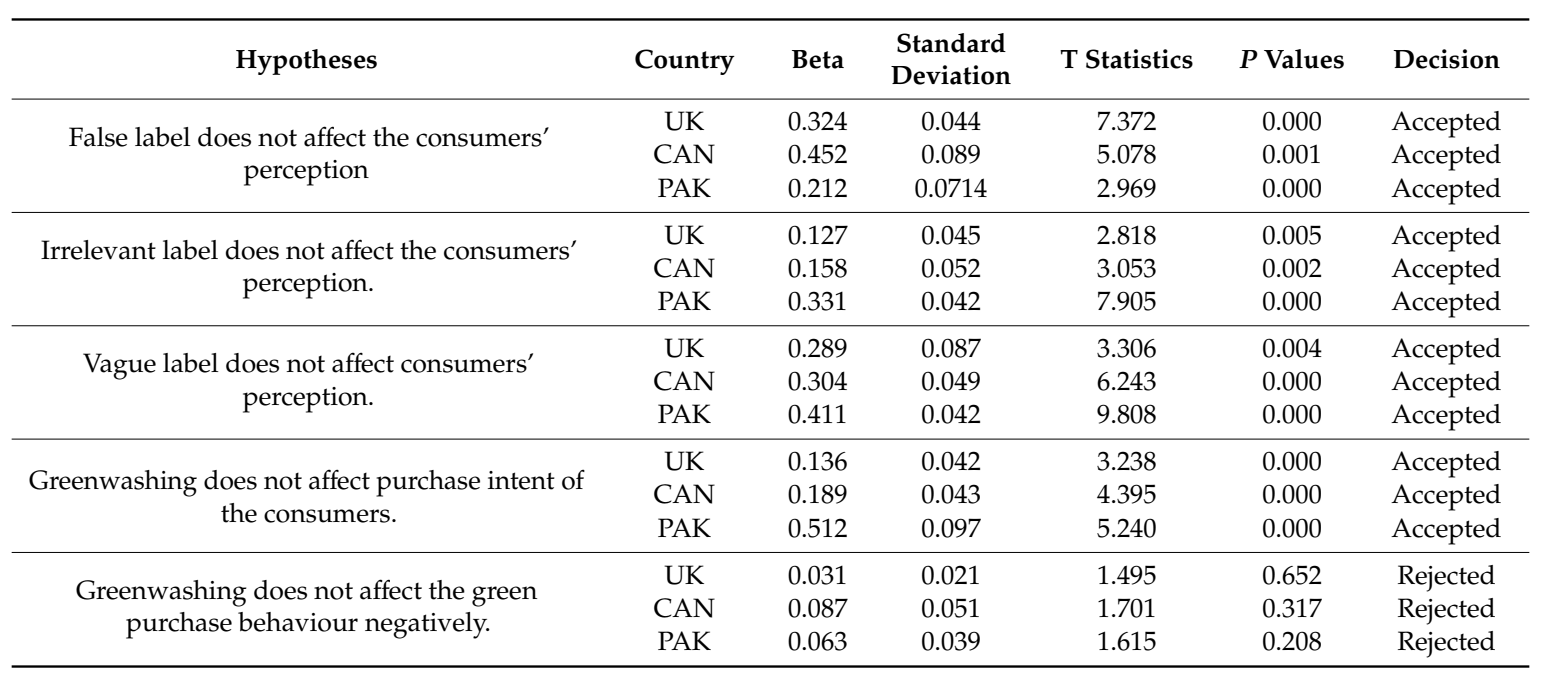




\section{Discussions}

The results showed that there is a statistically significant impact of false labelling on consumers' perception. In other words, consumers' perception is not affected by a false label as they are unable to distinguish a false label product despite being skeptical of greenwashing. The participants' perception remains the same despite the product claims being false therefore to larger extent finding supports the earlier studies of Halverson [1], Schmuck et al. [3], Leonidou \& Skarmeas [20], and Krafft [35]. Moreover, the study found that irrelevant labelling has a statistically significant impact on the perception of consumers in all three considered countries, which means that the present findings are aligned with the previous work of Halverson [1], Leonidou \& Skarmeas [20], Parguel et al. [32], and Krafft [35]. In other words, the perception of the consumers is reported to remain the same despite the product claims being irrelevant. It also reflects that irrespective of the type of country, the consumers, in general, still tend to buy and consume products having irrelevant information. Even, if consumers are skeptical about such information, they would still fall into the trap of consuming. There is also evidence that they perceived greenwashed products to be sustainable, because, despite some irrelevant information, they still view them as overall sustainable products. In fact, the skeptical and high environmentalists were also unable to distinguish greenwashing (irrelevant labelling) when asked about it. As a result, the present finding confirmed that skeptical consumers are unable to distinguish greenwashing (irrelevant labelling attribute), therefore the findings are aligned with the work of earlier studies of Halverson [1], Schmuck et al. [3], Nyilasy et al. [11], Chan [18], and Krafft [35] while contradicting the findings of Leonidou and Skarmeas [34]. On the other hand, the study also found that high environmentalists more often perceive greenwashing as sustainable products, therefore in this regard, the present study contradicts the work of Nyilasy et al. [11], Chan [18], and Brouwer [33].

Moreover, the study found a statistically significant impact of vagueness on the perception of the consumers. In other words, the consumers' perception is not affected differently, even if the products have vague features in the details. Trust is found to be an issue among the consumers and despite being skeptical, they are still able to trust some features of the greenwashed products [33]. This is to some extent, confirmed by the present findings. The lake of awareness is a reason behind opting to use a greenwashed product [33]. This is contradicted. On the other hand, the fact that consumers are unable to identify greenwashed products as being deceptive $[10,35]$, is supported by the present study. Despite being skeptical, consumers consider greenwashed products as being environmentally friendly and sustainable [1]. This notion is supported by the present study. Although consumers are skeptical and aware, they opt to consume such products. Thus, the study partially differs from the work of earlier studies [11,32], because earlier studies found a lack of awareness as a reason for consuming greenwashed products. This study supports the findings of Terra Choice [16] while contradicts the work of Nyilasy et al. [11] that consumers' perception tends to improve on being skeptical about greenwashing.

The study further found that the purchase intent of the consumers is not affected differently by greenwashed products. It was found that irrespective of greenwashing, even if identified by the consumers they still opt to buy the greenwashing product. In fact, it could be argued that greenwashing might perhaps not alter the intent negatively, but once the consumers are exposed to such greenwashed products, they are more likely to buy it. After exposure to a greenwashed advertisement there are likely chances that consumers would buy the product more often [35], which is a notion supported by this study findings. Interestingly, the study opposed the notion that highly environmentally conscious individuals would be able to identify and recognize greenwashed products as less sustainable and avoid using them [10]. The study opposed this argument because those who considered themselves high environmentalist were still using the greenwashed products, and surprisingly, using more often than low and moderate environmentalists. Furthermore, the study found that greenwashing does negatively affect green purchasing behaviour. This reflects that the consumers who identified themselves as green purchases to any degree reported that their green purchase behaviour is negatively affected by such greenwashed products. As a result, they become more skeptical of all types of products, yet, they have 
not much intent to further explore and therefore consume greenwashed products on viewing that some aspects might be sustainable. It has been proved that the greenwashed products directly and negatively affect the green purchase behaviour of consumers.

This study found that subjective knowledge about false claims is not sufficient to detect claims. Therefore, the study is aligned with the argument of references $[3,10,35]$. This study to a more significant extent is aligned with previous work $[11,18,35,42-45]$ by confirming that the green purchase behaviour tends to be negatively affected by greenwashing. In the light of the ARI model, it was proved that the underlying rational and affective mechanisms of the consumers are activated after seeing greenwashing products but are unable to restrain themselves from using them. Furthermore, greenwashing products activate an affective persuasive mechanism of the consumers, not only is the evaluation positive even if they identify the greenwashing attributes, yet they more strongly use the products, so the attitudinal appeal further drives them to use the product. Thus, the present work partially supports the work of the earlier study [3]. Nevertheless, that study was related to the greenwashing advertisement while here the study used the products to see if the visual in the adverts is more compelling or in actuality even after touching the product and using the description; they are still drawn towards using it. This is a new development in the studies related to greenwashing. The present findings indicate that greenwashing products are perceived as sustainable by consumers across all three countries. The cognition and effect are found to be qualitative and varying but the concurrent persuasive mechanism of the consumers drives them to perceive and view things in a specific manner. The positive impact of effect and positive impact of rational cognition simultaneously influence the attitude of the consumers [3], the postulate is confirmed through the present findings. The consumers' response is influenced through labels rather than advertisements, which is a new finding and contradicts the postulate of the ARI model [3]. The emotional persuasion is found to be more syncretic cognition than rational persuasion; therefore, this study partially supports the argument of Petty and Cacioppo [41].

\section{Conclusions}

The awareness, trust, and effectiveness of consumers are largely affected by the greenwashing products. The overall conclusion can be drawn that all other participants have high perceptions for sustainable products even if the product has been labelled correctly or not. The present study used a ranking scale to determine the degree of environmental consciousness, and different participants viewed themselves as high, low, and moderate environmentalists. Results found High environmentalists being more skeptical than Low and Moderate environmentalists, are more likely to fall into the trap of identifying greenwashing products as sustainable. Participants reported that products are believed to be sustainable due to the overall perception that some features are at least sustainable of greenwashed products. It is further supported by the statistical evidence that purchase intent is not affected by greenwashing. It is therefore concluded that the label irrespective of being correct or not tends to affect the consumers' perception. The results are found statistically significant in that false labels are useful in affecting the participants' trust by making it more believable to be sustainable. More than vagueness and irrelevance, false labels have a stronger impact in affecting the overall perception of the consumers. Interestingly, false label products are found to be trustworthy enough compared to the irrelevant and vague labels, and, therefore, have a significant impact on product perceptions while no significant difference were found in purchasing intent across all labelled items. Moreover, no greenwashing attributes such as false labelling, irrelevance, and vagueness are statistically and significantly different from one another in affecting the purchase intent of the consumers. It means that all are equally significant in affecting the purchase intent.

It is also reported that younger people have less trust and often believe greenwashing is problematic in comparison to older people. Consumers were found to be vulnerable and more sensitive when their attention was drawn towards greenwashing. There is a need for educating consumers and improving the policies to ensure consumers recognize real labels when using greenwashing products in daily 
life. It has also been substantiated that greenwashing creates a negative impact on green purchase behaviour, which means that sustainable aspects along with the environment of operations, are likely to be affected adversely.

\section{Limitations and Future Directions}

The limitation of this research includes the use of a categorical scale for measuring the degree of environmentalists and green purchasing. It would be interesting that future studies consider classification through a latent variable with a scale where individuals could express to what extent, they identify themselves with different aspects reflecting the trait of environmentally friendly and green purchasing. Future studies should consider a continuous scale to measure the magnitude. Similarly, the use of the Chi-Square test only revealed the general test results of three categorized groups as high, moderate, and low environmentalists and green purchasers but it limits us in finding whether exactly the differences between these groups are more prominent or less. The future studies should consider this aspect by comparing the three groups such as high vs moderate, high vs low, and moderate vs low. The future studies should consider the residuals of each crossing to gain further insight into the significant differences between categorized groups. Furthermore, the environmentalism perhaps could have been measured through a degree scale rather than categorizing it through a ranked scale. This way, it could have been effective in finding actual opinion rather than perceptions. Nevertheless, with the available resources, the adopted technique was more suitable for the present case at hand. The sample is another limitation of this study. It would be interesting if future studies consider the people profile by exploring the green consumers who do not opt to go to shopping malls. The present sample provides a generalized view, whereas profile consideration by investigating the research phenomenon from the total green individuals who do not go to shopping malls could provide more specific results.

Life and research are a long learning process, and we learn from our mistakes so we can improve in future approaches. Therefore, we learn that the exclusion of some key authors might have limited our findings to a certain extent. In addition to that, we used particular literature for questionnaire development at the expense of some key literature. Perhaps, higher credibility can be attained if empirical studies [28-30] are considered. Thus, we see that in this article, there are some methodological challenges and this study recommends that future researches consider those unused studies. Perhaps, they might come up with something different with exciting results. Future research must consider more strategic approaches by using validated literature to develop the variables of interest. This study explored the global perspective but did not opt to include the measurement invariance comparison test to assess whether the structural model in the three samples s directly comparable or not. It is a limitation and we proposed that future studies should consider the use of the measurement invariance comparison test to assess if the samples are directly comparable or not. Our focus was on the global perspective while considering categorical data as well as ordinal data; hence we did not consider using direct comparison of the samples through structural modelling. By considering this suggestion, future studies perhaps might discover some interesting findings through direct comparison.

\section{Theoretical Contributions}

This research paper contributes to the literature in the following ways; one of the findings is "green purchase behaviour is affected by greenwashing". It is a new contribution to the literature of sustainability and greenwashing through green purchase behaviour. This also opens the avenue for researchers to investigate in the direction further by using green marketing dimensions such as green brand image, green brand love, and green brand loyalty concerning green purchase behaviour. There are previous studies that have identified that greenwashing reduces green purchase behaviour [42-45]. However, those studies did not use a theoretical model such as ARI to investigate the phenomenon. The field of green marketing benefits from the findings of this study by learning about the age groups viewing sustainable and greenwashed products differently. The study explores environmentally conscious consumers by ranking them and exploring their perceptions, which was not explored before 
in the literature. Therefore, it can use the study to develop marketing strategies on the psyche of consumers in a certain age bracket to expand green marketing further.

\section{Practical Contributions}

It has been identified that green purchase behaviour can be increased by reducing greenwashed products, thus, there is solid evidence at hand about the negative impact of greenwashing. Consumer cynicism towards green products can be increased by communicating fairly and educating the consumer about different types of greenwashing. The effectiveness of green marketing relies heavily on the trust and awareness of the consumers on green claims, which can be attained by reducing greenwashing. The study practically found that affective reasoning enhances the perception and behaviour of the consumers in a certain manner. Previous studies used the ARI model only concerned visual adverts while leaving behind the investigation if products of different types of labels are mixed with sustainable ones, how the consumers can effectively perceive it. The factors causing greenwashing must be identified and a strategy formulated to exterminate them. The companies must not over-promise when conducting green marketing. Reduction of greenwashing will increase ultimately green purchase behaviour.

Author Contributions: M.U. presented the conceptual theme and developed the research questions. A.u.H. articulated the draft, developed research hypotheses, wrote the manuscript and data analysis. All authors have read and agreed to the published version of the manuscript.

Funding: This research received no external funding.

Conflicts of Interest: The authors do not have any conflict of interest.

\section{Appendix A}

Table A1. Survey questions.

\begin{tabular}{l}
\hline Environmentalists \\
\hline To what extent do you identify as an environmentalist? [E1] \\
How important is it for you to strive to live a sustainable lifestyle? [E2] \\
\hline Consumer perception \\
\hline Do you think greenwashing is a problem? [CP1] \\
I trust product claims [CP2] \\
\hline Green purchasing behaviour \\
\hline To the best of your knowledge, how environmentally friendly would you consider this product? [GPB1] \\
In your opinion, how common do you think greenwashing is? [GPB2] \\
I think Green products are relevant to my shopping needs [GPB3] \\
I am aware of Green products [GPB4] \\
Easy availability of the Green products [GPB5] \\
I think Green products are of superior quality [GPB6] \\
Value for money [GPB7] \\
\hline Green purchasing \\
\hline When purchasing products, how often do you look for green alternatives? [GP] \\
\hline False labelling \\
\hline To what extent are you aware about this product being eco-friendly? [F1] \\
To what extent do you trust the "Certified Green" label provided on the product? [FL2] \\
Would seeing this label make a difference in your decision to purchase it? [F3] \\
To the best of your knowledge, how environmentally friendly would you consider this product? [F4] \\
To what extent you think consuming this product will bring you more satisfaction [F5] \\
\hline
\end{tabular}


Table A1. Cont.

\begin{tabular}{l}
\hline Vague labelling \\
To what extent do you trust the "recycling" label provided on the product? [V1] \\
Would seeing this label make a difference in your decision to purchase it? [V2] \\
To the best of your knowledge, how environmentally friendly would you consider this product? [V3] \\
\hline Irrelevant labelling \\
To what extent do you trust the "No CFCs" label provided on the product? [IL1] \\
To what extent are you aware about this product being non-toxic [IL2] \\
Would seeing this label make a difference in your decision to purchase it? [IL3] \\
To the best of your knowledge, how environmentally friendly would you consider this product? [IL4] \\
\hline
\end{tabular}

\section{References}

1. Halverson, R. Consumer Perceptions of Greenwashing: Understanding Awareness, Trust, and Effectiveness. Bachelor's Thesis, University of Colorado, Boulder, CO, USA, May 2018.

2. Wu, S.I.; Lin, S.R. The effect of green marketing strategy on business performance: A study of organic farms in Taiwan. Total Qual. Manag. Bus. Excel. 2016, 27, 141-156. [CrossRef]

3. Schmuck, D.; Matthes, J.; Naderer, B. Misleading Consumers with Green Advertising? An Affect-Reason-Involvement Account of Greenwashing Effects in Environmental Advertising. J. Adv. 2018, 47, 127-145. [CrossRef]

4. Budinsky, J. "It's Not Easy Being Green": The Greenwashing of Environmental Discourses in Advertising. Can. J. Commun. 2013, 38, 207-226. [CrossRef]

5. Delmas, M.; Burbano, V. The drivers of greenwashing. Cali. Manag. Rev. 2011, 54, 64-87. [CrossRef]

6. Federal Trade Commission. Guides for the Use of Environmental Marketing Claims; Final Rule. Fed. Regis. 2012, 77, 62122-62132.

7. Feinstein, N. Learning from Past Mistakes: Future Regulation to Prevent Greenwashing. Bost. Col. Env. Aff. L. Rev. 2013, 40, 229-257. [CrossRef]

8. Carlson, L.; Grove, S.J.; Kangun, N. A Content Analysis of Environmental Advertising Claims: A Matrix Method Approach. J. Adv. 1993, 22, 27-39. [CrossRef]

9. Lyon, T.P.; Maxwell, J.W. Greenwash: Corporate Environmental Disclosure under Threat of Audit. J. Econ. Manage. Strate. 2011, 20, 3-41. [CrossRef]

10. Newell, S.J.; Goldsmith, R.E.; Banzhaf, E.J. The Effect of Misleading Environmental Claims on Consumer Perceptions of Advertisements. J. Market. Pract. 1998, 6, 48-60. [CrossRef]

11. Nyilasy, G.; Gangadharbatla, H.; Paladino, A. Perceived Greenwashing: The Interactive Effects of Green Advertising and Corporate Environmental Performance on Consumer Reactions. J. Bus. Ethics. 2014, 125, 693-707. [CrossRef]

12. Parguel, B.; Benoit-Moreau, F.; Russell, C.A. Can Evoking Nature in Advertising Mislead Consumers? The Power of 'Executional Greenwashing'. Int. J. Adv. 2015, 34, 107-134. [CrossRef]

13. OECD. Key short-term Economic Indicators: Private Consumption (Volume). 2019. Available online: https://stats.oecd.org/index.aspx?DatasetCode=KEI (accessed on 19 September 2019).

14. CEIC. Private Consumptions: \% of GDP. CEIC Data. 2019. Available online: https://www.ceicdata.com/en/ countries (accessed on 11 September 2019).

15. Bonnell, A. Consumer Attitudes Toward Green Brands Reach All-Time High Marketing a Sustainable Brand Story: The Impact of an Environmentally-Conscious Business Model. 2015. Available online: https://blog.marketresearch.com/sustainability-in-america-consumer-attitudes-towardgreen-brands-reach-all-time-high (accessed on 4 September 2019).

16. Terra Choice. The Sins of Greenwashing-Home and Family Edition-A Report on Environmental Claims Made in the North American Consumer Market. Und. Lab. 2009, pp. 1-31. Available online: http://faculty.wwu.edu/dunnc3/rprnts.TheSinsofGreenwashing2010.pdf (accessed on 9 September 2019).

17. Hirose, Y. Social Psychology of Environment and Consumption; Nagoya University Press: Nagoya, Japan, 1995.

18. Chan, R.Y. Determinants of Chinese consumers' green purchase behavior. Psych. Market. 2001, 18, $389-413$. [CrossRef] 
19. Joshi, Y.; Rahman, Z. Factors Affecting Green Purchase Behaviour and Future Research Directions. Int. Strat. Manag. Rev. 2015, 3, 128-143. [CrossRef]

20. Leonidou, C.N.; Skarmeas, D. Gray Shades of Green: Causes and Consequences of Green Skepticism. J. Bus. Ethics 2017, 144, 401-415. [CrossRef]

21. Fliegelman, J.E. The Next Generation of Greenwash: Diminishing Consumer Confusion Through a National Eco-Labeling Program. For. Urb. Law J. 2010, 37, 1-72. Available online: https://ir.lawnet.fordham.edu/ulj/ vol37/iss4/2/ (accessed on 21 September 2019).

22. Aji, H.M.; Sutikno, B. The Extended Consequence of Greenwashing: Perceived Consumer Skepticism. Int. J. Bus. Inf. 2015, 10, 433-468.

23. Goh, S.K.; Balaji, M.S. Linking green skepticism to green purchase behavior. J. Clean. Prod. 2016, 131, 629-638. [CrossRef]

24. Wood, M.E.J. Exploring Consumers' Experiences with Corporate Greenwashing. Ph.D. Thesis, Walden University, Minneapolis, MN, USA, May 2015.

25. de Vries, G.; Terwel, B.W.; Ellemers, N.; Daamen, D.D.L. Sustainability or profitability? How communicated motives for environmental policy affect public perceptions of corporate greenwashing. Corp. Soc. Res. Env. Manag. 2015, 22, 142-154. [CrossRef]

26. Davis, J.J. Consumer Response to Corporate Environmental Advertising. J. Consum. Mar. 1994, 11, $25-37$. [CrossRef]

27. Tariq, M.Z. Impact of Green Advertisement and Green Brand Awareness on Green Satisfaction with Mediating Effect of Buying Behavior. J. Manag. Sci. 2014, 8, 274-289.

28. Morgan, R.M.; Hunt, S.D. The commitment-trust theory of relationship marketing. J. Market. 1994, 58, 20-38. [CrossRef]

29. Flavián, C.; Guinalíu, M.; Gurrea, R. The role played by perceived usability, satisfaction and consumer trust on website loyalty. Inform. Manag. 2006, 43, 1-14. [CrossRef]

30. Yang, H.; Lee, H.; Zo, H. User acceptance of smart home services: An extension of the theory of planned behavior. Ind. Manag. Dat. Sys. 2017, 117, 68-89. [CrossRef]

31. Paço, A.M.F.; Reis, R. Factors Affecting Skepticism toward Green Advertising. J. Advert. 2013, 41, $147-155$. [CrossRef]

32. Parguel, B.; Benoît-Moreau, F.; Larceneux, F. How Sustainability Ratings Might Deter "Greenwashing": A Closer Look at Ethical Corporate Communication. J. Bus. Ethics 2011, 102, 15-28. [CrossRef]

33. Brouwer, A. Revealing Greenwashing: A Consumers' Perspective. 2016; pp. 45-252. Available online: https://files.eric.ed.gov/fulltext/ED571577.pdf (accessed on 21 September 2019).

34. Chen, Y.-S.; Chang, C.-H. Greenwash and Green Trust: The Mediation Effects of Green Consumer Confusion and Green Perceived Risk. J. Bus. Ethics 2013, 114, 489-500. [CrossRef]

35. Krafft, J. Greenwashing: An experimental study about the effects of misleading and deceptive environmental claims in advertising. Bachelor's Thesis, University of Gothenburg, Gothenburg, Sweden, December 2014.

36. Stokes, S.A. Deception in Environmental Advertising: Consumers' Reactions to Greenwashing. Master's Thesis, Kansas State University, Manhattan, KS, USA, 2009. Available online: http://krex.kstate.edu/dspace/ bitstream/2097/1462/1/StaciStokes2009.pdf (accessed on 14 September 2019).

37. De Jong, M.D.T.; Harkink, K.M.; Barth, S. Making Green Stuff? Effects of Corporate Greenwashing on Consumers. J. Bus. Tec. Comm. 2018, 32, 77-112. [CrossRef]

38. Buck, R.; Anderson, E.; Chaudhuri, A.; Ray, I. Emotion and Reason in Persuasion: Applying the ARI Model and the CASC Scale. J. Bus. Res. 2004, 57, 647-656. [CrossRef]

39. Buck, R.; Chaudhuri, A. Affect, Reason, and Involvement in Persuasion: The ARI model. In Konsumentenforschung; Weinberg, P., Ed.; Verlag Franz Vahlen: Munich, Germany, 1994; pp. 107-117.

40. Chen, S.; Chaiken, S. The Heuristic-Systematic Model in Its Broader Context. In Dual-Process Theories in Social Psychology; Chaiken, S., Trope, Y., Eds.; Guilford Press: New York, NY, USA, 1999; pp. 73-96.

41. Petty, R.E.; Cacioppo, J.T. The Elaboration Likelihood Model of Persuasion. In Advances in Experimental Social Psychology; Berkowitz, L., Ed.; Academic Press: New York, NY, USA, 1986; pp. 123-205.

42. Kalafatis, S.P.; Pollard, M.; East, R.; Tsogas, M.H. Green marketing and Ajzen's theory of planned behaviour: A cross-market examination. J. Cons. Mark. 1999, 16, 441-460. [CrossRef]

43. Kim, Y.; Choi, S.M. Antecedents of green purchase behavior: An examination of collectivism, environmental concern, and PCE. Adv. Cons. Res. 2005, 32, 592-599. 
44. Chen, Y.S.; Chang, C.H.; Lin, C.Y.; Lai, P.Y. The negative impact of greenwash on green purchase intention. In Proceeding of 21st ISERD International Conference, Shanghai, China, 7 December 2015.

45. Chen, Y.S.; Chang, C.H. Enhance green purchase intentions. Manag. Dec. 2012, 50, 502-520. [CrossRef]

46. Leblanc, D.C. Statistics: Concepts and Applications for Science; Jones and Bartlett Publisher: Sudbury, UK, 2004; Volume 2.

47. Rumsey, D.J. Statistical literacy as a goal for introductory statistics courses. J. Stat. Edu. 2002, 10. Available online: http://www.amstat.org/publications/jse/v10n3/rumsey2.html (accessed on 10 November 2019). [CrossRef]

48. Jamal, S. Statistics Problems and Practice Edition 2013 for B.Com; Ahmed Academy: Karachi, Pakistan, 2013.

49. Haque, A.U.; Kot, S.; Imran, M. The moderating role of environmental disaster in relation to microfinance's non-financial services and women's micro-enterprise sustainability. J. Sec. Sus. Iss. 2019, 8, 355-373.

50. Kot, S.; Haque, A.U.; Kozlvski, A. Strategic SCM's Mediating Effect on the Sustainable Operations: Multinational Perspective. Organiza 2019, 52, 219-235. [CrossRef]

51. Haque, A.U.; Nair, S.L.S.; Kucukaltan, B. Management and Administrative Insight for the Universities: High Stress, Low Satisfaction and No Commitment. J. Pol. Manag. Stud. 2019, 20, 236-255.

52. Imran, M.; Haque, A.U.; Rębilas, R. Performance Appraisal Politics and Employees' Performance in Distinctive Economies. J. Pol. Manag. Stud. 2018, 18, 135-150. [CrossRef]

53. Haque, A.U.; Aston, J.; Kozlovski, E. The impact of stressors on organisational commitment of managerial and non-managerial personnel in contrasting economies: Evidences from Canada and Pakistan. Int. J. Bus. 2018, 23, 152-168.

54. Kot, S.; Haque, A.U.; Kozlovski, E. Mediating Effect of Strategic Supply Chain Management on Social and Environmental Sustainability: Evidence from SMEs of Canada, Iran and Turkey. Int. J. Sup. Chai. Manag. 2019, 8, 105-117.

55. Ringle, C.M.; Wende, S.; Becker, J.M. SmartPLS 3. 2015; SmartPLS GmbH: Boenningstedt, Germany, 2018.

56. Hair, J.F., Jr.; Hult, G.T.M.; Ringle, C.; Sarstedt, M. A primer on partial least squares structural equation modeling (PLS-SEM): Sage Publications. 2016.Hu, L.t.; Bentler, P.M. Fit indices in covariance structure modeling: Sensitivity to underparameterized model misspecification. Psy. Met. 1998, 3, 424.

57. Pallant, J. SPSS Survival Manual. A Step by Step Guide to Data Analysis Using SPSS, 23th ed.; Open University Press: Maidenhead, UK, 2016.

58. Nunnally, J.C. Psychometric Theory; McGraw-Hill: New York, NY, USA, 1978.

59. Hamid, M.R.A.; Sami, W.; Sidek, M.H.M. Discriminant Validity Assessment: Use of Fornell \& Larcker criterion versus HTMT Criterion. J. Phys. Conf. Ser. 2017, 890, 1-5.

60. Haque, A.U.; Aston, J. A Relationship between Occupational Stress and Organizational Commitment of I.T Sector's Employees in Contrasting Economies. Pol. J. Manage. Stud. 2016, 14, 95-105. 